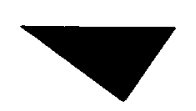

\title{
Metodologia da análise de imagens
}

\author{
Tania Aparecida de Souza Vicente \\ Universidade Federal Fluminense
}

\section{Análise das imagens}

Presentes na variedade de produtos culturais expressivos de determinada sociedade, as imagens possuem dois espaços determinantes para a sua percepção: o olhar de quem a produz, ou do autor, e o outro de quem a recebe. Sabemos que as percepções aproximadas ou equivalentes podem ser provocadas pela contemporaneidade dos sujeitos, "aqueles que compartilham do seu programa de produção".

Interpretações diversas, mesmo aquelas produzidas por sujeitos que participam do mesmo tempo histórico e mesmo grupo cultural, são capazes de recriar sentidos e significados. É através do compartilhamento da produção/percepção das imagens visuais que percebemos e formamos as séries conexas de imagens.

Sobre este importante conceito tomamos o trabalho do professor Eduardo Neiva "Imagem, história e semiótica", de 1993. Derivado da iconologia mas que é "tanto uma propriedade da história como uma característica inevitável da ação dos signos". A idéia pode ser definida como "uma espécie de semelhança de família, um piscar de unidade, em expressões diversas", reconhecida dentre o conjunto de produtos culturais de uma época. Neiva apresenta novos olhares sobre a historiografia e justapõe aos estudos iconológicos a experiência da análise semiótica.

"As imagens nos vêm de séries conexas continuamente transformadas. A analogia preside as conexões. São essas séries conexas que nos permitem, de possibilidade em possibilidade, interpretar as imagens. Um passo importante para a interpretação de imagens deve recompor as séries conexas. Duas formas de tempo estão em atividade: o presente que caracteriza as possibilidades materiais da imagem e $o$ 
desdobramento da série, passo a passo, que cria as idéias de história, passado e tradição." (Neiva, 1993:12)

A interpretação das imagens através das séries conexas permite 0 reconhecimento das analogias entre as imagens ${ }^{2}$. Analogias possíveis de serem detectadas devido ao nosso pré-conhecimento ou reconhecimento adquirido do referente, do processo cultural que as produziu e, de uma maneira mais imperceptivel, devido a nossa própria inserção neste processo de produção. O que Neiva vai chamar de "legado histórico e experiências conceituais ou cognitivas" parece constituir os elementos necessários para uma primeira análise .

Abriremos aqui um primeiro parênteses para tentar explicar methor o que entendemos por interpretação. O filósofo Edmond Ortigues levanta questões pertinentes às diferentes formas de se realizar a atividade de interpretação articulando suas diversas categorias. Afirma que a interpretação consiste na tarefa de intermediação dos significados presentes em uma obra qualquer, mais do que num processo de significação propriamente. Desta forma, a significação teria a função de criação, enquanto a interpretação "tenta fazer compreender a um certo público aquilo que foi dito ou escrito por outrem. Ele [o intérprete] não é o autor da palavra ou da escrita nem o destinatário final da mensagem. É um contato, um mediador." (Ortigues)

A interpretação, seguindo esta visão, é uma relação estabelecida entre o texto ou expressão original com o texto ou expressão que surge a partir do movimento de interpretar. Este movimento atua como chave de leitura da expressão original. Então temos um enunciado secundário que só existe em função do primeiro. Esta relação, que poderíamos denominar umbilical, só seria rompida se dela surgissem novos significados, ou seja, se em vez de um processo de descrição simples de uma obra, operássemos processos de análise fundadoras de novos sentidos.

Imediatamente associamos este esquema de pensamento aos níveis de análise apresentados por Panofsky. Embora a idéia de colocarmos separadamente a ação de interpretar com a de significar seja uma forma um pouco cartesiana de tratar o assunto.

Ainda, segundo Ortigues, a análise "comporta uma parte de interpretação, isto é, de reformulação do vocabulário descritivo nos termos de uma hipótese teórica destinada a trazer à luz de certas relações entre os dados observáveis."

Porém, o importante em sua concepção consiste em que ela permite pensar a multiplicidade de interpretações possíveis, não pela sim- 
ples subjetivação, e sim pela capacidade de se estabelecer classes de correspondências.

"Se tais obras se prestam a múltiplas leituras, não é porque tenham vários "sentidos", mas sobretudo, porque o seu sentido explícito cria classes de correspondências que permitem com o livro interpretar a vida e com a vida interpretar o livro. Interpretar então, quer dizer : fa. zer ver certas correspondências entre universos ou estados de coisas, entre os quais não nos percebiamos até então nenhuma ligação direta." (Ortigues: 225)

Observamos que não existe uma fronteira muito visivel entre interpretação e significação. Durante o trabalho de análise interpretamos e, ao fazê-lo, desvendamos seus métodos de construção dos significados - na iconologia de uma forma. na semiótica de outra. De qualquer modo, após a realização da análise o objeto já não é mais o mesmo, não será percebido da mesma maneira como antes. porque ao analisálo resignificamos, atribuímos novos valores e signos.

Observando as categorias envolvidas na análise das imagens, ressaltamos o avanço conceitual do termo estilo que, se no nosso discurso diário é compreendido como forma de expressão individual, o termo ganha, no texto de Neiva, o aditivo de "concepções culturais coletivas corporificadas nas imagens". Assim, estilo é entendido a partir da idéia de " classe que é transgredida enquanto sintoma do estado geral do espírito de toda uma época c não mais o sentimento de um individuo." (Neiva 1993:14)

\section{Análise iconológica}

Admitimos que a tarefa de interpretação, pensando principalmente nas imagens contemporâneas, implica num esforço constante de tentar nos colocar como um espectador privilegiado que procure assistir ambos os niveis - percepção e produção. Na interpretação das imagens contemporâneas estaremos, muitas vezes e ao mesmo tempo, impregnados por eles, porque "imagens são simultaneamente reflexo e esboço de comportamentos". Tal questão ganha nova dimensão quando pensamos sobre o eslorço proposto pela metodologia de Panofsky.

Comentando Panofsky, Bazin afirma que:

"O que ele procura, em verdade é uma vez descoberto o significado. entrever o plano de fundo levantado por qualquer especulação humana, mergulhando assim no universo do mito, infindavelmente renovado, ora por efeito de referência, ora por efeito de inversão, isto é, o universo das metamorfoscs."(Bazin 1989:184) 
Embora a iconologia tenha sido fundada pelo alemão Aby Warburg, foi Panofsky o seu grande difusor. Ele pertenceu ao Instituto que funcionava na biblioteca de Warburg, trabalhando junto com Ernest Cassirer e Gustav Pauli. Em 1935 se incorporou ao Institut of Advanced Study da Universidade de Princeton em Nova York. (Bazin 1989:178)

A iconologia fundamenta-se em três níveis de significados das artes figurativas: o primário, onde consta a identificação e descrição das formas; o secundário ou convencional, que atesta os motivos artísticos com base em textos e documentos elucidativos, e o terceiro que é o da análise propriamente, sendo aquela que desvenda os valores simbólicos das obras e de sua época, "a análise é movente de ações e reações múltiplas que podem revelar toda uma proliferação de signos através das mais diversas civilizações e culturas." (Bazin 1989:179)

Aby Warburg apresentou o estudo da arte figurativa com a intenção de que ele não se limitasse a apenas um periodo histórico. A iconologia, segundo seu fundador, "pode estudar a Antigüidade, a Idade Média, em suas comunicações recíprocas." (Bazin 1989:179)

Ainda sobre os elementos que permitem análise das imagens, Neiva analisa apuradamente o método de Panofsky e resume:

"O significado das imagens é alcançável graças a uma mistura de erudição e quebra-cabeça, como a interação de hipóteses, deduções e provas fatuais, análoga à solução de enigmas que atormentam os detetives." (Neiva 1993:15)

O método iconológico refere-se à tradução vocabular, à decifração de códigos obscuros à primeira vista, pois a familiaridade com as imagens é insuficiente para uma verdadeira análise.

Atrás dessa idéia, Panofsky sugere, como já foi colocado, três níveis de desenvolvimento de análise, ou seja, três fases hierarquicamente concebidas para o estudo dos significados das obras de arte cujo método tem sido apropriado também para outros gêneros de imagens, como as dos cinema, fotografia, imagens publicitárias.

Então em termos conceituais o método iconológico coloca a diferença entre significado e forma, que pode ser também tratado como forma/percepção formal e conteúdo.

A forma estaria relacionada ao mundo visual, "parte de uma estrutura geral de cor, linhas e volume", enquanto a identificação do significado divide-se em primário e secundário. O primário requer o reconhecimento de conjunto das formas com os motivos artísticos, este último compreendido como a atmosfera, um sentimento. Assim, terí- 
amos que levar em consideração que formas puras são ligadas a estados emocionais ou qualidades expressivas e "uma enumeração desses motivos constituiria uma descrição pré-iconográfica".

O significado secundário, o da percepção das convenções sócioculturais, seria a experiência da análise iconográfica relativa a um terceiro nivel de compreensão das imagens. No dizer do próprio Panofsky, o terceiro nível requer "uma faculdade mental comparável a de fazer diagnóstico, uma faculdade que não sei descrever melhor senão usando o termo, bastante desacreditado de intuição sintética, e que pode estar mais bem desenvolvido num amador de talento do que num erudito estudioso." (Panofsky 1986:27)

Fora a polêmica da questão, o fato é que o próprio autor insiste em um controle da qualidade da análise através da efetiva consulta as fontes documentais escritas: textos de época, estudos aproximativos ao tema foco, legendas etc. Retornamos então as idéias de Neiva sobre a qual a iconologia "parte da tradição logocêntrica centrada no princípio do predominio da linguagem verbal sobre a figuração." (Neiva, p. 17)

Neiva interpreta o método iconológico definindo-o como o casamento dos motivos artísticos com temas ou conceitos, e a combinação das imagens com outras resultaria em histórias e alegorias - personificações ou símbolos.

Panofsky determina que a "identificação de tais imagens, história e alegorias pertence ao campo da iconologia, no sentido mais restrito da palavra. Na realidade, quando falamos vagamente de "conceito temático como oposto a forma", referimo-nos especialmente à esfera do conteúdo secundário ou convencional, isto é, ao mundo dos temas e conceitos específicos que se manifesta através de imagens, história e alegorias, por oposição à esfera do conteúdo do primário ou natural que se manifesta em motivos artísticos."( Panofsky 1986:2)

O terceiro nível da análise trata do significado intrínseco ou do conteúdo onde estão implicadas as apreensões do contexto da produção, dos fatores históricos "assumidos inconscientes por um individuo e condensados numa obra".

Além disso, podemos dizer que a crítica de Neiva estende-se pelo fato de que se a "descoberta" iconográfica já é uma interpretação, de resto, o necessário para o trabalho de análise seria a descrição tomada como um processo de agregação das formas visuais preliminarmente interpretadas na fase pré-iconográfica.

"A identificação pré-iconográfica permitiu que a simultaneidade 
das formas visuais fosse transformada na cadeia linear da descrição verbal. A descrição precisa já presumia um conhecimento estilístico das formas. $\mathrm{O}$ iconólogo pode, então, começar a traçar a linguagem cronológica da figuração. As séries conexas são assentadas. Para inseri-las numa série, a imagem precisa ser datada. Sem isso, não há como identificar sua participação numa seqüência cultural." (Neiva 1993:17)

\section{O conceito de representação na semiótica e na iconologia}

Tentamos traçar alguns pontos relevantes para uma comparação da teoria semiótica com a iconologia.

O conceito de representação pode ser tratado de acordo com as concepções de Pierce, cuja teoria provém de um modelo triádico de pensamento e que foge do paradigma kantiano, o conceito logocêntrico ${ }^{3}$ de representação.

Ernest Cassirer influenciou os estudos de Panofsky. Em sua filosofia predomina a linguagem. "Ela surge como necessária, natural e afiliada às sensações imediatas". As representações, derivariam do "lugar supremo da palavra", onde nomeação e $\log ^{\dagger}$ são condições $^{-}$ conceituais. Desta forma Neiva vai concluir que o nível iconográfico de análise das imagens identifica os textos como chave e ilustração para as configurações visuais e que o ato de representar é um processo incompleto que envolve mais do que convenções (Neiva 1993:22).

As etapas de produção sígnica, segundo Neiva, originadas da semiose de Pierce podem ser assim determinadas:

A primeira onde as hipóteses expressam as relações de comparação, relativa à natureza das possibilidades, considerada como o estágio de abdução, o ponto inicial do conhecimento, expressão do que é possível.

A segunda que é a do nível do real, o que "experimentamos concretamente, onde o empírico aparece como um aspecto de ordem, normativo, sob a forma de conflito que se vale da natureza dos fatos efetivos". É o estágio lógico da investigação cognitiva, a dedução, onde as hipóteses são explicadas extraindo as conseqüências necessárias por meio das quais as conjecturas são testadas.

Por fim, a terceira classe situada como valor reflexivo que, mediando as representações, funciona como lei e tem a força das convenções - relações de pensamento as quais pertencem a natureza das leis vividas como convenções - indução. Avalia as hipóteses condutoras da reflexão. 
Assim, podemos entender o signo para além de sua definição usual, como algo que está no lugar de alguma, ou seja, podemos definilo como uma função triádica onde representações interagem.

$\mathrm{Na}$ função signo convivem, para Pierce, o signo veículo - base material que fundamenta a representação, o objeto, ou o que está representado, e o signo-interpretante - conexão interpretativa dos dois primeiros.

A noção de semiose de Peirce - ou a ação dos signos, ou ainda, os processos de interação cooperativa dos signos - está estritamente ligada à ação de séries conexas. Neiva vai explicar que elas. as séries conexas, como um princípio de análise, permitem a história e a semiótica aproximarem-se. Dessa forma, podemos entender que as séries conexas relacionam iconologia e semiótica.

"As imagens são autônomas. Nas imagens as representações, na medida precisa do processo de semiose que cria a dimensão histórica. A semiose é uma série constituida e montada, intencionalmente ou não. $\dot{E}$ através de um processo de semiose que os signos adquirem sentido. O resultado final é um processo obsessivo de multiplicação infinita e acumulativa como a sucessão de acontecimentos que se relacionam e se influenciam." (Neiva 1993:29)

\section{Condições da análise}

Trataremos neste item sobre as condições da representação visual, passando a confiar na viabilidade de um método de análise que se apoiaria em fatos mais concretos e mais facilmente comprováveis.

O texto do filósofo inglês Max Black vai tentar explicitar as condições que permitem uma imagem representar/mostrar um objeto. Trata da fragilidade do conceito de representação quando confrontado na análise de fotografias, sempre tomadas como exemplo.

Suas idéias vão decompondo e revelando a fragilidade dos pressupostos até então admitidos como razoáveis para a compreensão do processo de representação das imagens. Condições normalmente aceitas para que, por exemplo, uma fotografia represente uma cena qualquer.

\section{História causal}

A história causal diz respeito à etiologia do meio de produção das imagens, do processo físico de elaboração fotográfica, do cinema, do video e da pintura, para citar alguns produtos. Esta primeira condição investigada, mostra a impossibilidade de qualquer descrição genética 
da origem de uma imagem ser capaz de garantir a identificação fiel do processo de representar. A história causal pode ser considerada insuficiente e até mesmo desnecessária.

As principais razões para essa afirmativa seriam: desconhecer as propriedades visuais da imagem não impedem a percepção dos aspectos visuais; as informações sobre a produção da imagem não fazem parte do tema mostrado; mesmo que o meio de representar não seja identificado $\mathrm{F}$ continuaria mostrando $\mathrm{S}$; mesmo que o processo de elaboração da imagem modificasse o fato seria reduzido em apenas uma nova maneira de $\mathrm{F}$ mostrar $\mathrm{S}$ (hoje temos um constante desenvolvimento tecnológico com novos parâmetros e processos para a criação de imagens, mesmo que estas, por sua vez, continuem a possuir um formato final tradicionalmente conhecido, fotografia, cinema, vídeo).

\section{Informação incorporada}

A quantidade e qualidade da informação presente em um registro imagético como pressuposto de análise, implica na aferição do conceito de informação. Neste caso destacamos do texto a informação de acordo com os sentidos dados pela teoria matemática, ou um conceito estatístico, ou denominada por Max Black de informação seletiva.

La situación típica a la que se aplica la teoria matemática es aquella en que un determinado sentido de "mensages" posibles, que pueden concerbirse como caracteres alternativos en un "alfabeto" (letras, cifras o impulsos de energia), com los que no esta necesariamente vinculado significado alguno, se codifican como "senales" para ser transmitidas a través de un "canal de comunicación" y para su recepción, decodificación y exacta reproducción final del "mensaje"original". (Black 1991: 139)

A informação seletiva diferencia-se sensivelmente do sentido usual da palavra (informação denominada por Black de substantiva é a que possui o significado corrente). A seletiva afasta-se ainda da informação semântica, também analisada. Em um último instante, ambas , semântica e seletiva aproximam-se, pois reiteram o mesmo tipo de concepção, ou seja, dois enunciados analisados à luz da teoria semântica ou estatística podem conter o mesmo grau de informação e possuir conteúdos diversos.

"Se tenemos dos enunciados de estrutura lógica paralela, por ejemplo, "Me lhamo blanco" y "Me thamo negro", una definición aceptable de la información semântica asignará la misma información semântica a cada uno de los enunciados". (Black 1991:143) 
Ambos os conceitos, informação semântica e informação seletiva, são destacados para a compreensão do processo de representação das imagens.

A análise das informações substantivas em um primeiro momento parece factivel porque contempla o conteúdo da imagem. Porém, se considerarmos que a imagem possui vários significados e que eles seriam construídos a partir da relação entre a imagem, o objeto e o observador, a análise conteudística perderia fôlego. O caráter polissêmico das imagens visuais e áudiovisuais confere ao analista o estatuto de autor de novas interpretações.

Lembramos ainda que análise conteudística pertence ao universo textual, que limita o aprofundamento dos estudos relativos a imagens e reafirma o tradicional lugar de ilustração, mantido até hoje para as fontes iconográficas da história. Também os meios em imagem nos estudos da comunicação (a televisão, assim como o cinema. embora objeto de vários estudos, é investigada sob o ponto de vista das conseqüências socioculturais) possuem um lugar secundário em relação por exemplo à imprensa jornalística.

Nos estudos sobre a informação o mesmo acontece, há claramente uma sobreposição das preocupações teóricas para os documentos verbais textuais em comparação com documentos registrados em outros suportes ou linguagem.

\section{As intenções do autor}

Outra forma de abordar o fenômeno da representação das imagens é o de verificar as intenções do produtor ou do autor ao elaborar um quadro, uma fotografia, ou produzir imagens em um filme. Seria, num primeiro momento, tratar da ideologia, ou ideologias que levaram o autor a produzir a imagem.

Para verificarmos a intenção presente na construção de determinada imagem, ou saber se a intenção do autor foi alcançada, seria necessário que de antemão estivéssemos bastante conscientes e seguros da representação que determinada imagem oferece, ou seja, este seria exatamente o intento final da análise, e não um meio.

“... en que no existe forma alguna de indentificar la intención predominante que no consista en recurrir precisamente a la idea del tema de un posible cuadro, que es lo que a referencia a la intentaria justamente acalar" (Black 1991:147)

\section{Semelhança}

Sem conseguir abandonar a "circularidade" oferecida por este úl- 
timo elemento de análise de texto, Max Black assinala os modos possiveis de investigar a relação entre o objeto e sua representação através dos diversos sentidos incorporados pelo conceito de semelhança.

Recorrer ao caráter de semelhança da representação com o referente como condição de se aclarar o processo de construção das imagens ou tentar elucidar as semelhanças de uma imagem com seu referente sugere um caminho idêntico àquele que fazemos ao perguntar o que faz uma imagem representar algo. Retomamos ao princípio quando tentamos alcançar o objetivo.

Porém chegamos a uma chave de leitura do problema levantado.

Max Black considera acertadamente o conceito de representação como um conceito "guarda-chuva", o qual abriga todos os critérios acima considerados tomando-os como valores equivalentes, pois " forman un entramado donde ninguno de ellos puede considerarse por separado como necesario o suficiente, pero todos ellos son pertinente en el sentido de servir potencialmente para una aplicación idónea del concepto de representación figurativa." (Black 1991:167)

A análise das imagens não deve ser feita através da verificação de uma condição apenas, todas são importantes para responder com clareza sobre o modo de representação das imagens, assim, "será preciso, por el contrario, emplear una investigación menos pulcra y más exigente acerca de la producción y valoración de los objetos artísticos en el interior de los "estilos o modos de vida" (Black 1991:168)

\section{A construção do objeto}

Uma das questões principais da análise é o da construção do objeto de estudo. Entendemos que para ser levada a bom termo ela prescinde de um projeto de estudo. Tentar analisar as fontes em imagens sem ter como base hipóteses a serem provadas e defendidas representaria navegar sem rumo em meio a um mar de múltiplas possibilidades. A interpretação da imagem relacionada e orientada por um projeto condiciona a elaboração de uma metodologia adequada, a escolha de conceitos e de teorias norteadoras das conclusões.

A explicação ou interpretação histórica não se faz ao largo de uma noção hipotética. A argumentação científica, incluindo a oriunda das análise das imagens, caminha pelas fontes a partir de questões antecipadamente referenciadas.

O que queremos ou buscamos provar quando analisamos uma fotografia, por exemplo, vai influenciar a escolha do método e na formação das séries conexas. 
Lembramos ainda de um outro ponto que deve ser observado com cuidado, que é o da análise feita pela história ou pela comunicação, em comparação com as várias categorias de interpretação. $O$ trabalho do analista rompe muitas vezes com antigas verdades e argumentos $\mathrm{e}$ que as pesquisas e análises, mesmo quando partem de uma mesma premissa, chegam a resultados diferentes.

A análise das imagens é um comentário exegético que por conseguinte constitui-se em uma hipótese a qual responde as questões colocadas relativas a um texto ou a um documento (Ortigues, 222). O interesse por certas questões por conseguinte é determinada pela época, pelo grupo a que pertencemos. A história que construímos, mesmo quando olhamos para o passado distante, é uma história do nosso tempo, cujos temas são escolhidos dentre aqueles mais caros em termos politicos, sociais e culturais.

A análise da imagem pressupõe escolhas a serem feitas, as quais acarretam qual o melhor método a ser aplicado. A semiótica ou a iconologia, ou até o diálogo entre as duas como sugere o professor Eduardo Neiva, pode nos oferecer um campo conceitual importante para compreendermos os mecanismos de construção dos significados. As condições gerais estudadas por Max Black, que fazem com que uma imagem mostre um objeto, se afirmam como suficientes se mediadas e colocadas em niveis equivalentes de importância.

Os problemas que possivelmente possam ser apontados na iconologia, sua origem dual, kantiana, cujas origens remetem a uma predominância da linguagem verbal, podem ser atenuados com a importância dada à dimensão histórica das imagens.

Acreditamos que a análise das imagens constitui um campo a ser desenvolvido e que a interdisciplinaridade pode se mostrar como uma grande aliada.

\section{Bibliografia}

ANDERSON, Perry. Zona de compromisso. São Paulo: Unesp, 1996.

AUMONT, Jacques. A imagem. Campinas: Papirus, 1996.

BARTHES, Roland. A camara clara. Rio de Janeiro: Nova Fronteira, 1984.

BAZIN, Germain. História da história da arte. São Paulo : Martins Fontes, 1989. 
BLACK, Max. Cómo representan las imágenes? In: GOMBRICH, E. et al. Art, perception and reality. Baltimore: John Hopkins Univ. Press, 1991.

GINZBURG, Carlo. Mitos, emblemas e sinais. São Paulo: Companhia das Letras, 1991.

GOMBRICH, E. Arte e ilusão. São Paulo: Martins Fontes, 1986.

GOMBRICH, E. El espejo y el mapa: teorias de la representación pictórica. In: La imagen y el ojo. Madrid: Alianza, 1991, pp. 163-199.

JOLLY, Martine. Introdução à análise da imagem. Campinas: Papirus, 1996.

MAUAD, Ana Maria. Através da imagem: fotografia e história interfaces. Tempo, v. 1, n. ${ }^{\circ} 2,1996$, pp. 73-98.

NEIVA, Eduardo. Imagem, história e semiótica. Anais do Museu Paulista (nova série), n. ${ }^{\circ} 1,1993$.

NEIVA, Eduardo. Sob o signo da história: resposta a meus comentadores. Anais do Museu Paulista (nova série), n. ${ }^{\circ} 1,1993$.

158 ORTIGUES, Edmond. Interpretação. IN : Enciclopédia Einaudi. Lisboa : Imprensa Nacional/Casa da Moeda, 1987, v. II, pp.218-233.

PANOFSKY, Erwin. Estudos de iconologia. Lisboa: Estampa, 1986.

\section{Notas}

1 Imagem formada pelo ouvinte de acordo com a realidade sugerida pelo veículo.

2 Segundo Neiva, a noção de semiose em Pierce está ligada à ação das séries conexas.

3 Neste sentido representação é definida como processo restrito às convenções materiais. Neiva vai explicar que a visão logocêntrica não considera a dimensão da atuação dos sujeitos. "As constrições materiais do pensamento conferem às representações coletivas seu caráter objetivo que transcende a dimensão singularizada do ator social."

4 Pois, nomeação, ato de nomear, definida por Cassirer, é a experiência constitutiva do próprio mundo, sua apreensão e representação simbólica (Neiva 1993:22). Logos, no pensamento kantiano que afirma que "as impressões são ordenadas como se sofressem a ação daquilo que os gregos na Antigüidade Clássica identificavam como logos, o criador da unidade que autoriza a própria presença do mundo." (Neiva 1993:22) 